\title{
¿DE DÓNDE ES LA VOZ? ELOY TIZÓN: LA VOZ CANTANTE
}

\author{
Katalin Kulin \\ Universidad Eötvös Loránd \\ kkulin@gmail.com
}

RESUMEN: Se propone describir la técnica narrativa que Eloy Tizón desarrolla en $L a$ voz cantante, novela de 2004 que se construyó por dos líneas que forman una extraña amalgama de una historia de amor y una serie de encuentros faústicos con el diablo; la función clave se la asigna a un narrador no identificable.

PALABRAS CLAVE: memoria, identidad, diablo, historia de amor, destino

\begin{abstract}
This is an attempt to describe the narrative technique used by Eloy Tizón in his 2004 novel, La voz cantante which is made up by two major lines forming a strange mixture of a love story and a series of Faustian episodes with the devil as protagonist; the key function is assigned to an unidentifiable narrator.
\end{abstract}

KEYWORDS: memory, identity, devil, love story, destiny

La obra empieza con el Diablo, que se le presenta al protagonista, Eldel, en el tren, por cuyos recuerdos nos enteramos de que, de niño, ya se había encontrado una vez con él. En una novela es inusitado un arranque de este tipo, pues el lector y así, yo misma contaríamos con más acontecimientos extraordinarios o, al menos, con otros giros imprevisibles suscitados en el estado espiritual y anímico del protagonista. Es verdad que mis expectativas al respecto no se verán satisfechas por el amor que surge entre Eldel y Mónica Friser, pero la extraordinaria profundidad y autenticidad de este sentimiento se ofrecen prometedoras y nos invitan a seguir por la senda que nos traza la novela. La pareja huye del padre de la muchacha - adinerado y, por tanto, poderoso, que se opone a estas relaciones - asumiendo privaciones y miseria, hasta que el señor Friser los encuentra e, incluso, le impone su voluntad a Eldel. Se lleva consigo a la hija, y la hace casar con otro. Eldel lo llega a saber, sin embargo, esto no despertará en él ningún deseo de tomar cartas en el asunto. Termina sus estudios. Enseña en la universidad. Vive solo, y al cabo de un tiempo, deja de sufrir aceptando resignadamente su vida solitaria, una vida que también después de jubilarse seguiría viviendo de la misma manera.

La verdad es que con este desenlace simplemente me sentí embaucada. No era lo que prometía el comienzo. Sin embargo, el nivel indudablemente elevado del escrito no me dejó tranquila. Volví a leer el libro, y lo hice con un cuidado poco común en un lector. Quería saber si cabía o no alguna explicación en el proceder del escritor para que el valor de su decisión inicial, que negaba toda racionalidad por su amor excepcional e increíblemente exigente, quedara reducido a rutina, no solamente por el lento enfriamiento de los sentimientos - lo que indudablemente asumiríamos con dolor, aunque como algo conocido -, sino porque tanto las dimensiones cósmicas del encuentro con Lucifer como el impulso que hacía volar al amor hasta las nubes, quedaron rebajados a la rutina lenta y tediosa de todos los días.

En la primera lectura, mi decepción me dejó la impresión de que prácticamente la mitad de la novela estaba formada por la vida de Eldel tras su separación. Pero a la segunda lectura, descubrí que simplemente había podido confundirme la lenta monotonía de esa vida. La aparición del demonio y del amor maravilloso, testimonio 
del encuentro perfecto de la pareja, me impelían rápidamente hacia adelante y me convencieron de que el recuento sobre la prolongada vida que sigue a la separación abarcaba casi el mismo número de páginas.

Pero el error puede traer también utilidad, si no nos creemos infalibles. Así que, procedí al análisis detallado. Para empezar, ¿quién cuenta los acontecimientos? Al comienzo, el autor no lo dice todavía. Así es como si su mensaje no lo redujera a una sola persona. El nombre del anotador aparecerá solo cuando este se enamora del personaje que viene con el nombre de Mónica Friser. Llama la atención que a la mujer amada nunca la menciona solo por su nombre de pila. Quizá con ello quiera destacar su condición de persona única e inconfundible. Mónica pueden ser muchas, pero Mónica Friser es un nombre que va con su cédula de identidad personal. Otra explicación posible, y de ninguna manera injustificada, es que tal vez haya en la muchacha algo del padre, del señor Friser. Por eso, ella está dispuesta a casarse con el hombre que él le designa. Es una circunstancia interesante que Mónica es más alta que Eldel, lo que, ya en sí, señala que la relación tiene algo de particular, un rasgo que difiere de lo usual. Pasaríamos fácilmente por alto el uso consecuente de Mónica Friser, aunque no es habitual que un enamorado llame así a su pareja. En todo caso, es llamativo que el escritor apunte a la importancia del nombre en una forma tan misteriosa.

El señor Friser se divierte con el nombre de pila de Eldel; ora le dice Daniel, ora Fidel o Manuel. Así como suena el nombre de Mónica, siempre acompañado de su apellido aludiendo a la identidad personal de la muchacha, de la misma manera, el señor Friser pretende borrar la identidad de Eldel llamando a veces Manuel, a veces Daniel o Fidel o al Gabriel que tiene enfrente o a ese cualquiera. A alguien que no vale la pena distinguir del montón de desconocidos anónimos.

En la historia contada por Eldel no solo nos encontramos con saltos hacia atrás o hacia adelante, tan frecuentes en la literatura moderna, sino que tampoco resulta fácil darnos cuenta de cuándo lo narrado es realidad y cuándo es sueño, puesto que el sueño trata también de sucesos, así como lo imaginado aparentemente también brinda más información sobre los eventos mismos. Evidencia su igualdad de rango el hecho de que en la vida del yo sobra su distinción, a la par que se justifica el método narrativo aplicado por el escritor que, eventualmente, presenta la realidad inmediata en forma indirecta o metafórica, elevándola, de esta manera, a un nivel superior, de lo carnal a lo espiritual. Además, para eludir la estrechez de lo explícito, no cierra con muerte la imposibilitada vida común y esta nada ha perdido del sentimiento que queda de su vigor en la monotonía sin incidentes del día a día.

Los tres períodos de la vida de Eldel son: el encuentro con el mundo exterior incomprensible y canalla (la muerte de la gallina), la lucha con lo interior, incomprensible, pero que ha de comprenderse (caminar por la cornisa con los ojos vendados) y la etapa de la razón encontrada (el amor) que abarca no más de diecisiete años, a pesar de que el milagro recibido lo conserva encerrado en la botella de los cuarenta años. Los primeros y terceros períodos indican el ingreso en el mundo, así como la experiencia de la plenitud de la vida; en ningún caso está solo Eldel, primero le hace compañía la gallina, después en el tercer período, Mónica Friser. En el segundo, aparece solo, pero entonces opta por elegir la vida. La fase siguiente, los cuarenta años están caracterizados por la soledad. Los discípulos no son sus compañeros, solo en principio han tomado nota de su existencia. Pero cada día que pasa es como si ya se hubiera jubilado y como si se hubiera quedado excluido del mundo feliz o desesperanzado, del mundo en que se lucha constantemente. La vivencia fundamental de los ancianos solitarios es quedar invisibles para los otros. Sin declararlo - algo poco 
corriente en la literatura -, el escritor nos pone frente al estado de la existencia libre de deseos, en que ya no se aspira a nada, al contrario, se acepta tranquilamente la rutina cotidiana, en suma, en que le da igual si existe o no.

Esto pone en duda las dimensiones del tiempo y del espacio, determinantes de la existencia terrenal. Ya en el primer capítulo de la novela leemos: "Las leyes del espacio y del tiempo cambian. [...] El espacio puede plegarse como un biombo y el tiempo puede extenderse como una alfombra." (p. 17.) En esta concepción, el tiempo y el espacio son una propiedad del mundo que él ve ya solo desde el margen. Más importante que la categoría humana del tiempo es el viento, el que "...ya existía antes que las estaciones, que es contemporáneo con Dios...", y "habrá también cuando desaparezcan los hombres y los animales de esta tierra”. (p. 22.) Así, si bien antes apuntábamos que elevaba lo corporal a lo espiritual, ahora hemos de reconocer que el escritor se afana a colocar todo lo experimentado por encima no solo de su propia existencia, sino también de toda la humanidad. La oración citada estira desde el "Génesis" hasta el libro del "Apocalipsis de San Juan", una historia bastante sencilla y reducida a algunos momentos.

Dentro de ello, el amor es la vivencia que todo lo entreteje, una vivencia profunda y duradera. Entre los dos jóvenes, el amor no se desarrolla en la forma habitual de nuestros días, ya que ambos esperan y no se comunican durante un buen tiempo. Sienten instintivamente que podrían arriesgar algo muy valioso. No es el típico atractivo que suele surgir en el encuentro entre un muchacho y una muchacha, sino algo extraordinario - una pequeña señal también nos lo advierte: la joven es más alta -, un sentimiento inexplicable y connatural con el milagro. Este amor, que originalmente había causado decepción, ganará precisamente su indudable credibilidad, ya que ni los cuarenta años con sus días sucesivos y reiterativos, o sea, ni el tiempo ni la rutina, pudieron eclipsar en Eldel (el hombre) su resplandor.

Sin el amor de Mónica Friser habría sido incomprensible el curso de su vida ya que, como dice, ella es la figura de la alfombra, la melodía secreta, la viga maestra, la clave de bóveda de sus palabras. A ella le aplica Eldel la misma metáfora que al tiempo, aquello de ser una alfombra extendible, sugiriendo con ello que nunca cesará de colmar y cubrir todo el ser de Eldel. Con la piedra angular que impide el derrumbe del edificio, la Biblia formula el papel decisivo de Jesús, la fuerza del amor que todo lo sostiene. Con ello asemeja el yo el amor que siente por Mónica Friser y que sustenta su vida.

De nuevo consigue revivir el pasado, la circularidad del tiempo, lo que el presente acumulado sobre el pasado enriquece no solo con novedades, sino también con escándalo. No explica lo que es tal escándalo. Podemos suponer que se refiere a haber quedado truncada la posibilidad de vivirse dicho amor. Al mismo tiempo, la circularidad demuestra que para Eldel todo persiste como una realidad constante, como él lo dice, disfruta del potencial de retorno, y ve, incluso vive, todos los instantes del tiempo pasado juntos.

La autorreflexión - el llegar a ser adulto por el arrepentimiento -, generada por el milagro del amor, cuya vigencia eterna generalmente salvaguarda la muerte, ahora ni los cuarenta años de soledad le ha restado resplandor. Gracias a la inusitada concentración de fuerzas de estas dos experiencias humanas determinantes, fácilmente queda inadvertida la manera casi singular de hacer perceptible la soledad y la vejez. La soledad no se caracteriza por las quejas o el dolor, - lo que, desde luego, sería un tema literario mucho más trivial - sino que significa una existencia sosegada, invisible para todo el mundo, una existencia que se ha vuelto rutina. Eldel está fuera de la vida, aquella vida que se detuvo 40 años atrás en el eterno martes del metro. 
El mundo que no admite el milagro será representado por el señor Friser. Esto es incluso más inusitado, puesto que el propio señor Friser también había conocido el amor, pues nunca logró superar la muerte de su esposa. Un representante típico del mundo financiero, que no conoce otro amo que el beneficio económico, es implacable a la hora de privar a su hija de su enamorado. Con esta figura, no se justifica relacionar la pérdida por la esposa fallecida. Pero no hay que suponer inconsecuencia en el escritor. El señor Friser ha experimentado la inclemencia del mundo. Quizá por esto quiera brindarle a su hija una vida ordinaria, exenta de grandes sentimientos, para que ella nunca tenga que experimentar la muerte del milagro. Pero de todos modos, con él nos llegan los días corrientes infectados de maldad. No se puede tomar posesión de lo perfecto.

Este acontecimiento, contradictorio con lo tildado de normal, pero, al mismo tiempo, intensivo y candente, es una vivencia que identifica al protagonista con el escritor - acaso no sea injustificado decir autor en vez de escritor - y apunta a esa interrogante no destacada en la novela de que, además del amor, toda la vida de Eldel estará acompañada por la voluntad de escribir. Algo ha empezado y se pone a contar a espaldas del yo, “... contra mi voluntad incluso, y que va escribiéndose solo sobre el folio en blanco con el ritmo y la fatalidad que él decide.” (p. 34.) Pero ¿quién es este él? No lo sabemos, solo sospechamos que algún poder sobrenatural-muchos creadores lo asumen así - dirige su pluma, pincel o cincel. Esta misteriosa intervención justifica el carácter imperecedero y sempiterno del arte - mientras que tras las lumbreras de la ciencia y la filosofía a lo sumo quedan solo algunas ideas -, y es por eso que nuestro respeto va dirigido al planteamiento de la interrogante y a los esfuerzos que siguen para desarrollarlo y traer resultados siempre nuevos, pero nunca definitivos. No es que el artista sea más inteligente, o de ser así, tal vez lo sea por reconocer sus propios límites y aceptar la misteriosa orientación. El comportamiento por mí cuestionado al principio y luego acallado que reemplaza los milagros de la vida y su fuerza explosiva quizás reciba absolución e, incluso, crédito total, porque Eldel entiende que ni ahora ni antes la acción podía atribuirse a él, sino solo a ese no nombrado él. El milagro, el milagro del amor, no dependía de sí mismo, como tampoco su vida solitaria. La voluntad humana es poca para la determinación de la vida y lo que el escritor demuestra con el caso de Eldel, es que un hombre como él ni siquiera es capaz de discutir con el señor Friser.

El amor y la escritura están entretejidos por el recuerdo que mantiene a los dos con vida. La distancia de cuarenta años debería convertir en pasado la vivencia de juventud, pero como apunta: "Sueño los mismos sueños de entonces, de hace décadas, y huelo el olor del puerto y las fábricas de conservas ... esparciendo sus fragancias... era verano. Nos despertaban con sus sirenas..." (p. 93.) "Oigo rugir el parquet del suelo... en nuestro último apartamento alquilado..." (p. 94.) Ambas partes citadas atestiguan una percepción de tiempo actual donde el escritor utiliza el pasado solo para describir circunstancias relacionadas con el instante vivido en presente. La escritura es necesariamente en pasado gramatical, pero el amor del yo es ahora eterno. Estos tiempos, se disuelven y entremezclan dentro de la misma oración. A su vez, mediante esta mezcla se hace posible conocer lo que ocurre con los dos amantes destacando estos hechos del orden de los procesos supeditados a tiempos puntuales.

La singular concepción temporal de la existencia inicial y de la que ya va opacándose queda manifiesta en el hecho de que era martes cuando se encontró en el metro con el diablo, mucho después de la separación de los amantes, y es miércoles cuando sueña que el señor Friser le ofrece dinero para que deje a su hija y le apunta con un arma. A la pregunta que hace Eldel al despertar sobre el día que era su adorado, le 
responde que miércoles y que el día siguiente sería jueves, pero ese jueves no llegará jamás. Martes y miércoles conservan dos vivencias determinantes: a ellos no los separa tanto el tiempo como a dos días sucesivos de una semana, sin embargo, tras el martes no vendrá el miércoles seguido de jueves. En la realidad, la diferencia es de unos cuarenta años, pero este tramo está borrado por el recuerdo que se convierte en presente. "El pasado sigue estando presente." (p. 34.) - dice, antes de desarrollar la historia del diablo y del amor. Esta constatación encaja bien en el modo narrativo que confunde el orden temporal de los acontecimientos. No es capaz de separar el recuerdo del milagro y del diablo, la voluntad de describir y de escribir, es decir, de la posibilidad de su realización.

Todo esto hace que Eldel vea mejor las cosas y que tenga fuerza para confrontarse con la vida, la que lo torturará hasta dos veces con la impotencia de su amor. Primero a la edad de 5 o 6 años cuando su abuelo quiere celebrar su visita en su casa preparando para la cena a Valentina, la gallina que es su amiga adoptada. No puede impedir que la maten. Es la primera vez que siente remordimientos. Sus abuelos ríen al ver cómo se revuelve el cuerpo decapitado de la gallina, y él verá al diablo en la ventana de la cocina. "Valentina, desde entonces, no ha dejado de correr, sigue corriendo en mis sueños..." (p. 33.) La segunda vez, en el metro, el diablo devora sus facciones y el yo siente en ello el espionaje del tiempo. (p. 36.) El diablo es un niño rubio quien no hacía más que mirarlo (p. 37.) En él, Eldel se confronta consigo mismo cuando tenía cinco o seis años, quien tampoco podrá hacer nada para impedir que el señor Friser le privara de su amor. Ante este "asesinato" también resultará impotente.

Tras la vivencia de Valentina hubo otro hecho de gran importancia. Sin ello ni hubiera merecido el amor. Con los ojos vendados, camina a lo largo de una cornisa que está en el sexto piso. No quiere suicidarse sino "... estaba dispuesto a correr el riesgo absurdo de caer en la pesadilla de morir... solo para expulsar de mí aquel demonio." (p. 44.) Con este acto, quiere recuperar su autoestima, liberarse de sus remordimientos de conciencia por Valentina. Ya anciano piensa en Lucifer recordando que la última vez que se encontró con el diablo fue el martes. (p. 182.) Cree que nunca más se cruzará en su camino, aunque de inmediato rectifica: aunque también puede ser que ahora sea cuando el diablo está tramando su plan para hacerle caer en la trampa. Pero, a fin de cuentas, Lucifer también está tan viejo como él, sus flechas no darán en el blanco. A veces en primavera, en el aula, con la voz de una chavala hermosa, Mónica Friser le habla desde las profundidades del siglo. Siente como si retrocediera cuarenta años en el tiempo, y entonces el aire huele ligeramente a azufre. (Ello alude a que acaso añore recuperar para sí a la muchacha.) Cabe decir que su vida está en orden.

Aunque el escritor representa a Lucifer en otra persona diferente o en como una visión, su no retorno, su temeroso avanzar con los ojos vendados por la estrecha cornisa, demuestra que sigue llevando en sí mismo al Maligno, y de eso debe liberarse con la ayuda de empresa tan insensata. De hecho, no comete ningún pecado, pero tiene claro que para ello basta con la culpa de no impedirlo.

El diablo una vez es un rostro que mira por la ventana, otra vez, la tentación de saltar desde la cornisa, luego el pequeño rubio sentado en el metro, un viejo de la misma edad que el mundo, al que Endel identifica con Teobaldo, con su abuelo, quien es carne de su carne y sangre de su sangre y, finalmente, el Lucifer envejecido junto con él. En todas las formas, su yo es portador del embaucador, pero también a él se le resiste. Me he escapado del diablo, alguien me ha conducido de la mano - dice después de haber cruzado la cornisa sin caerse. En la lejanía, suena una campana (¿simple casualidad?) y la luz del sol inunda el aire "mudando los planos de todas las superficies... Hola, felicidad." (p. 49.) El maligno que surge para el cumplimiento de nuestra voluntad o de 
deseo es un obstáculo por superar. Nuestra época no ve así al hombre. El bien es la meta por alcanzar: la satisfacción carnal, la bella apariencia, el dinero, el éxito. De moral se puede hablar solamente de existir algún valor aceptado. Ninguno de los bienes señalados contiene normas éticas, y tal es así porque no apuntan al bien del semejante y no traen consigo una conducta social, una conducta comunitaria.

El pequeño rubio con quien ya adulto se encontrará en el metro lo llena de miedo. Extraña figura diablesca ya que al niño se le suele identificar siempre con la inocencia. No me enfrentaba con un niño, dice, sino con un tribunal. El de toda la infancia no difiere del de los viejos. "La mirada puesta en mí me inmovilizó a tal punto que dejé de apearme en mi parada, pero tampoco bajé en la siguiente." Se quedó allí hasta la estación final, donde empezaba una extensión con unas que otras casuchas miserables, un entorno incomprensible, soledad, el bosque donde se perdió y de donde no podía salir. Niños adormecidos por fumar pegamento, niños de rostro inexpresivo. Recuerda haber visto antes niños así en museos de Amsterdam o de Estocolmo. Entre ellos a un príncipe con sus enormes ojos muertos, el que despertando de un sueño había visto algo horroroso, su ciudad devastada por el enemigo o la tortura y ejecución de sus padres. Y vio indudablemente que a él lo miraban esos ojos. Descubre que esos ojos son de su abuelo, y en realidad los suyos propios de viejo. El horror provocado por su propia maldad y por el cual esperaba ganar el perdón poniendo en peligro su vida, la maldad del mundo reflejada en los ojos del príncipe, donde se refleja, se dilata en maldad del hombre, de la humanidad.

Por su debilidad de haber sido incapaz de tomar partido por una causa buena, paga como niño con la muerte de su amiga, la gallina, como joven con la pérdida de su amor, y quedará libre de otras pruebas solo gracias a a que Lucifer (que en él se esconde) ya está tan viejo como él. O sea, que entonces, su edad le ayuda a resistir a tentaciones ya sin fuerza.

El encuentro con el diablo se realiza en él mismo y por él mismo, por más que lo personifique una figura aparentemente independiente. El pecado está dentro de nosotros y el auxilio, aunque lo oigamos en nuestra alma, o en nuestro intelecto, llega de otro lugar. Se apresuraría en busca de su amante, pero comete un gran error al partir en dirección contraria. Gran error es una expresión demasiado grande para una simple falta de orientación, pero su sentido es simbólico. Si se aparta del camino correcto, le espera la muerte. Alguien o algo le advierte: "Vas a morir, vas a morir." (p. 70.) Cruza corriendo a la acera contraria. En ese momento cae un enorme trozo que adorna el edificio justo en el lugar que apenas acababa de dejar. La gente comenta el suceso, uno de ellos dice: "Hoy has vuelto a nacer." (p. 71.) Algunos escritores también dan cuenta de un incidente similar, pero entonces otros, si acaso hay alguien por allí, ni se dan cuenta de lo sucedido, o dan explicaciones evidentes. Solo aquel que ha vivido el milagro puede valorarlo. ¿Cómo es que los allí presentes tienen declaraciones tan diferentes? Uno habla de accidente, otro lo achaca a descuidos del gobierno, y una mujer hace una observación sorprendente y, en realidad, apenas comprensible: "La base del amor es la confianza." (p. 71.) Cabe saber que en el amor lo decisivo es la confianza, y esto es lo que se necesita para elegir el paso debido. Primero, en esto había errado Eldel, pero lo corrigió al ceder a una corazonada. La Biblia trae un ejemplo apropiado para las reacciones de la gente ante el milagro. Allí también la resurrección es siempre el resultado del milagro aceptado. Los presentes ni siquiera lo conciben o dudan, pero siempre hay también quienes tienen ojos para ver y atestiguarán la verdad del milagro ocurrido. Alguien de los presentes se compenetró profundamente con el milagro, y Eldel sintió que esta persona en su pensamiento se arrodillaba y le tocaba la ropa. "Entonces estuve más cerca de la santidad, debo resignarme - piensa - a que, igual que 
a los santos de radiante corona, yo también puedo estar rodeado del respeto que reciben los resucitados." La seriedad de la primera afirmación excluye el juicio irónico, pero la oración siguiente, tal vez, lo admita. Quizás el mismo Eldel cambie un poco de idea, como también todos solemos proceder así tras la primera valoración feliz de nuestra escapatoria.

El rumbo equivocado de Eldel es un gran error, porque, en realidad, aquí se trata nada menos que de una elección determinante del destino del hombre, de su trayectoria. El rostro que mira por la ventana, el chaval que arriesga la vida en la cornisa, el niño rubio en el metro, el decrépito Lucifer, son, en todo caso, él mismo: él es el tentador que se tienta a sí mismo, él es el que se desvía del camino que lleva al amor, y él es a quien el milagro lo salva de esto. Detrás de los giros que no dicen casi nada, el yo siempre está igualmente expuesto a elegir entre lo bueno y lo malo, como resume la Biblia (Santiago 1: 8): "El hombre de doble ánimo es siempre inconstante en todos los caminos." El pecado, el remordimiento y la penitencia impuesta para sí están a tono con las enseñanzas de la Sagrada Escritura. Su historia atestigua que el hombre aunque siempre lo intente - no decide sobre su propio destino. El milagro no recompensa al Eldel bueno, al que elige bien, todo lo contrario, el perdón, la gracia se concede a su "gran error".

El pecado, en la medida en que pueda tomárselo como factor novelístico, está rodeado actualmente de comprensión lo que impide a Eldel la autorrealización, ese rol central del yo y, por eso, la pasión no alcanza su objetivo o la carrera se va al traste. Pero desembocar en una crisis trágica determinante de la buena acción no realizada y calificada como pecado de segundo orden, simplemente con la presencia de Lucifer, no es característico de la literatura narrativa postmoderna. La apreciaciación bíblica según la cual no brindar ayuda es también un pecado, está lejos de la mentalidad del individuo saturado de sí mismo y concentrado solo en su propia persona. No obstante, últimamente vemos que la moral está ganando terreno en muchas obras, pero no dentro del marco de lo humano vaciado de contenido, sino en el orden de valores que apuntan más allá del hombre.

Hoy en día no creemos en los héroes, pues existe solamente el triunfador o el fracasado. No cabe duda, Eldel ha cedido sin más al señor Friser, igual que cediera frente al abuelo que le cortó el pescuezo a la gallina, sin embargo, en el orden de valores que sobrepasan lo humano, el señor Friser es un perdedor, ya que ha perdido a su amada esposa, y ni siquiera su voluntad que siempre se impone aquí ha conseguido alterar algo. En cuanto a Eldel, torpe en su lucha contra él, cierto que es un fracasado, pero es suyo el amor vivido y siempre presente en el tiempo circular. En su conducta no hay nada objetivamente heroico. Sin embargo, en la segunda lectura sentí lo que a pesar del final trágico de las grandes novelas del pasado sentía que, incluso en su caída, el protagonista resultaba ser un héroe. Formalmente, el Eldel de la novela estaría llamado a cumplir el papel de héroe, pero su debilidad lo hace inapto para ello. En realidad, el héroe no es él, sino el Hombre que jamás pierde en sí mismo su sentimiento de la plenitud, el Hombre que es más que el sí mismo.

En la cornisa, Eldel arriesga también a la muerte. Es una confesión de culpa de tal fuerza o una confrontación con su propia e inaguantable desvaloración que da testimonio de la debida humildad y, lógicamente, lo hace apto para el milagro del amor $\mathrm{y}$, después de privársele de este, para seguir la escritura, en lo que ya no le ayuda la condena de Mónica Friser. Pierde también los diarios. Pero su memoria es capaz de volver presente lo sucedido muchos pero muchos años antes. Aspira a que “... unas cosas se conviertan en cosas distintas a través de la alquimia del lenguaje y los sonidos... describir algo... es amarlo.” (p. 111.) Esta conversión en algo distinto no es 
menos que anular al maligno en el amor. Lo mismo intenta al escribir mucho más tarde sobre el señor Friser. Muchas veces nos declara su humildad: “... mi experiencia como narrador es limitada.” O: “Estoy narrando ya? No lo sé, pudiera ser que sí... No veo claro ni dónde empieza ni dónde termina esta historia." (p. 35.) "Lo difícil de verdad es seguir adelante... Avanzar, por un camino desconocido erizado de ramajes, con coraje y determinación." (p. 36.) No le está permitido descubrir mucho, sino solo lo imprescindible. Siente que a sus espaldas lo filman sin cesar y en los instantes de gran trascendencia siente el frío aliento de alguien en la nuca.

Mónica Friser le dio a Eldel un libro de poemas. Allí rezaba: "Con frecuencia al borde del abismo tomamos café con natillas." Como dice Eldel, este verso explica toda su vida, su separación de Mónica, el viaje y la guerra. El tiempo pasado con su amante es café y natillas, sin ella hasta resulta también positivo no caer en el abismo. La humanidad involucrada en las guerras despierta también a la consciencia de este abismo, e incluso se hunde en él. El autor advierte sobre la identidad entre el destino del individuo y del género humano al colocar a Eldel, que repite regresivamente sus vagabundeos con Mónica en el gran mundo, en un tren común junto con las masas que huyen. El verso mencionado fue escrito por un poeta perseguido, quien había sobrevivido sus viajes hechos por esos mismos parajes. Nosotros, viajeros del tren, aspiramos también a sobrevivir así, dice Eldel. Más de uno entre nosotros ha sufrido como enfermo del amor. Pero al borde del abismo, a menudo hemos tomado café con natillas.

Ni el amor ni la escritura han justificado la integración de la guerra en la historia. A no ser que para poder conectar el sufrimiento de Eldel con ese destino generalmente vigente y nunca exento de tormentos de la humanidad. Él arruinó su vida al carecer de fuerzas para enfrentarse al señor Friser, pero la mala decisión de la guerra, su error y la infinita miseria subsiguiente testifican que ni él ni nosotros somos incapaces de crear una vida feliz, por más que seamos solo pequeños puntos o enormes imperios. La felicidad es un regalo escaso. Eldel acepta humildemente que solo en su memoria puede conservarla sin poder poseerla.

Pasa una noche en una caravana como en la que vivió con su amada, y empieza a valorar lo que había recibido. Se hizo rico. Recibió seis meses de amor. No murió, dice. "Había tenido mi verano. Había vivido." (p. 164.) El tren por fin se detuvo, y él se encontró a las puertas de su ciudad natal. Después de una lluvia prolongada, salió el sol, la gente le hablaba en su propia lengua. Fuera de su maletín de viaje tenía consigo solamente el libro de poemas recibido de su amante, doblado en la página 160. Empieza a enseñar: "Se puede vivir con un puñal clavado en la espalda." (p. 166.) Encuentra su lugar (enseñar en la universidad) en la sociedad. El escribir atenúa su pena. Pasan los años, siempre hay guerras, entre insensatos y desesperados. No se rebela, no se siente víctima. Metáfora del amor inalterable es el puñal, el que lleva en la espalda hasta el final de su historia y, supuestamente, también después de ella.

En el inicio del penúltimo capítulo indica que sería sensato acabar allí el libro. Pero asume su "insensatez" y detalla cómo pasan los días de los dos o tres años que restan antes de su jubilación. Aquí sigue entonces esa parte sobre la cual ya he sostenido que no es un tema usual en la literatura. La rutina de la vejez, la edad pasada en soledad. Repetir cada día lo mismo es una suerte de disciplina, para que no se le desmorone a uno la vida. Refiere detalladamente lo que hace por la mañana, a mediodía y por la tarde, cuándo deja de trabajar, cómo pasa el tiempo antes de dormir. A veces antes de dejar la universidad va a la capilla y reza cinco minutos. Se arrodilla ante el Cristo crucificado. No es que alguien espere esto de él. Pero es que después “... respiro 
mejor.” (p. 172.) Su biografía trata de su alma, pero lacónicamente; las propias metáforas solo sirven para no tener que decirlo todo.

El fin de semana lo dedica a escribir (en la bañera hay para ello un tablero desarmable). En el edificio donde los moradores, en su mayoría solitarios, viven no hay contacto entre uno y otro. La comunicación está reducida a saludos. Muy pocas veces se acuesta con su amiga, y solo se utilizan mutuamente para satisfacer sus necesidades sexuales. Se alegra de no haber recurrido jamás a prostitutas. No es un santo-dice: soy mil, un millón de personas, mi nombre es multitud. Estoy bien, he cruzado el fuego sin quemarme. Privado del amor, solitario, sin embargo, puede vivir en paz, porque no se eleva por encima del resto, no cree que a él le corresponda más que a los otros. Los dos últimos capítulos, que no contienen ningún acontecimiento en especial, atestiguan la vida de millones digna de incluirse en el arte. De ahí nuestro agradecimiento al escritor. Pertenece a la experiencia propia de la vejez que los mayores y, por tanto, también Eldel, y los jóvenes vean de manera distinta el mundo. No entiende su lenguaje y ellos tampoco el suyo. Este es también un aspecto de vivir fuera del mundo. El otro, la ya mencionada rutina, la que asegura el orden anhelado. Los muros desnudos de la universidad sugieren este orden. Cita la tesis de la filósofa María Zambrano, quien sostiene que las aulas de la universidad son los lugares de la voz, y añade: los lugares de las palabras oídas. De su condición de profesor se desprende que su discurso interprete las obras maravillosas de la cultura, que a él y a sus alumnos "... nos hace estar en contacto cotidiano con lo sagrado." (p. 180.) Equipara el deterioro físico de la senectud con un resultado nada corriente. "A medida que las arterias se endurecen y el corazón sufre, eso espero, las palabras van saliendo luminosas." (p. 184.) De modo que ante la experiencia general, plantea Eldel, la pérdida del cuerpo puede implicar el enriquecimiento del espíritu.

Desde el día en el metro no ha vuelto a ver al diablo. Ya no le tiene miedo a Lucifer, está tan viejo como él. A veces trata de tentarlo, pero en vano. Vive en paz. La muerte del señor Friser le hace ver que ya no puede odiarlo.

No cree en la vida después de la muerte. La vida es de una sola vez, la vida es irrepetible. En toda su carrera universitaria, fuera donde fuera, siempre ha llevado consigo el volumen de poemas que recibió de Mónica Friser y que se ha hecho parte de él. Este cordón umbilical lo une a su pasado. Dejó que lo quemaran junto con él. Si abre el volumen lo llena la misma excitación erótica que Mónica Friser despertó en él ya la primera vez que la vio. Ahora mismo está enamorado de ella. ¿Y entonces no hay que creer en los milagros?

Esta es la última oración de la novela. ¿Milagro? ¿Qué palabra es esta? No tiene lugar en el mundo de los fracasados y triunfadores.

¿Y algo más? ¿Un fracasado habla de esto? ?A quien doblegó el padre adinerado?. ¿Es que acaso no fue Eldon el verdadero ganador?

Su escrito trata sobre el amor y sobre el tiempo. Allá en lo alto, ambos resplandecen, con luz enceguecedora. Desaparece el tiempo. Voz cantante. ¿La voz cantante de quién?

(C) Katalin Kulin

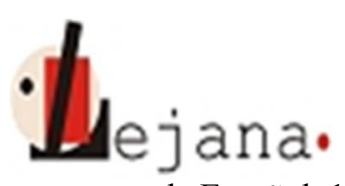

Universidad Eötvös Loránd, Departamento de Español, 1088 Budapest, Múzeum krt. 4/C

Recibido: 05 de agosto de 2015

Aceptado: 13 de octubre de 2015

Katalin Kulin: ¿De dónde es la voz? Eloy Tizón: La voz cantante 